\title{
SABELLA PAVONINA SAVIGNY VAR. BICORONATA HORNELL AND THE GENUS SPIROGRAPHIS VIVIANI (POLYCHAETA, SABELLIDAE)
}

\author{
By D. W. Ewer
}

(Text-figs. I-4)

Hornell (189I) described a variety of Sabella pavonina Sav., which he called bicoronata, from Hilbre Island at the mouth of the river Dee near Liverpool. This variety has recently been found at Plymouth where it may be trawled at Laira and in the Tamar estuary near Saltash Bridge. The variety is characterized by the inequality of the number of filaments of the two sides of the branchial crown.

The Sabellid genera Sabella Linnaeus, I758 and Spirographis Viviani, I805 as recently defined (Fauvel, 1927; Johansson, 1927) differ only in the inequality of the number of filaments of the two sides of the branchial crown. Hornell remarks that at first he was inclined to assign his variety to the genus Spirographis, but further examination showed that, apart from the number of branchial filaments, the worm differed in no way from Sabella pavonina. The specific descriptions of Sabella pavonina Sav. and Spirographis spallanzanii Viv. are also almost identical. Since the variety bicoronata shares with Spirographis spallanzanii one of the few characters which have heretofore been used to separate the two species, I have made a fresh examination of the three organisms to find further distinguishing characters. The descriptions of the species which are given below aim only at pointing out these differences and are not complete in themselves. Full descriptions may be found in such works as Fauvel (1927).

\section{SABELLA PAVONINA SAVIGNY ${ }^{1}$}

The two sides of the crown have an almost equal number of filaments. The total number of filaments is variable, there being usually between 25 and 50 on each side. Typical filament counts are 27-24, 29-30, 23-23 and 29-3I. The rachis of the crown from which the filaments arise is rolled through one complete revolution on each side (Fig. I A). When the crown is retracted the dorsal edges of the two sides of the crown at the level of the basal membrane are usually well separated. Viewed from the ventral surface the two sides of the branchial crown do not overlap, both turning inwards medially (Fig. $2 \mathrm{~A}$ ). The palps are straight, long and end in a fine tip (Fig. $3 \mathrm{~A}$ ). They are joined proximally by a fine membrane and are at least five times the length of this membrane.

${ }^{1}$ Johannson (1927) considers that this species should correctly be called S. penicillus L. I have here followed Fauvel. 
The dorsal collar fold arises immediately dorsal to the first chaetal bundle (Fig. I A). When reflected anteriorly the fold covers at least half the length of the peristomium. The ciliated faecal track runs along the dorsal mid-line of the thorax; where this track crosses the peristomium there is a shallow depression whose sides are never raised to form thin, clearly marked lips.

The ventral edge of the uncinal ridge of the second thoracic chaetigerous segment is separated from the dorsal edge of the ventral gland shield by at least half the length of the ridge.

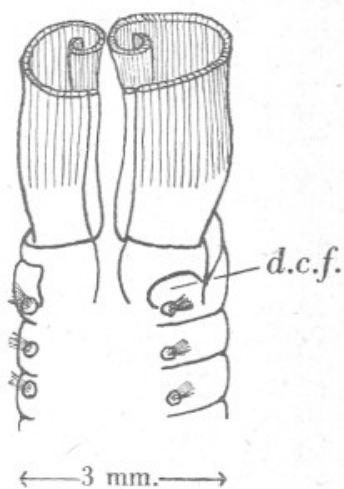

A

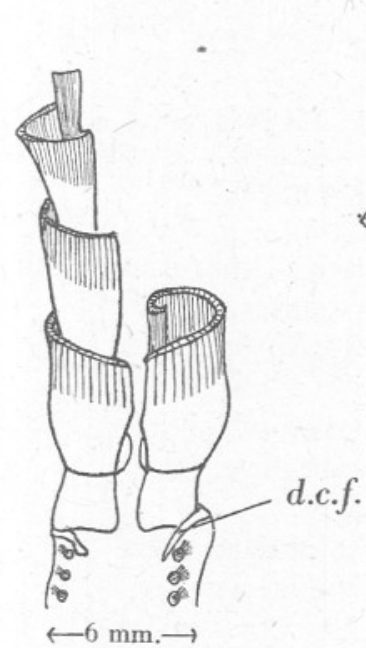

B

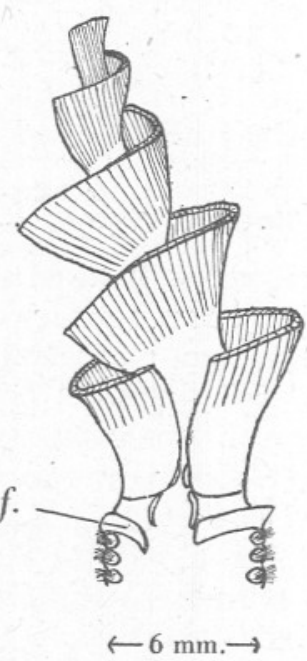

C

Fig. I. Diagrams showing the shape of the rachis of the branchial crowns of A, Sabella pavonina; B, its variety bicoronata; and C, Spirographis spallanzanii. All three specimens are viewed from the dorsal side. d.c.f. dorsal collar fold.

\section{S. PAVONINA VAR. BICORONATA HORNELL}

The two sides of the crown do not carry the same number of filaments. The proportions are variable. Typical counts on adult specimens are $4 \mathrm{I}-83$, $45-84,36-45$ and $43-52$. Hornell gives values of $30-61$ and $37-55$. The rachis of the crown on the greater side is spirally rolled and may make up to three complete revolutions. On the lesser side the rachis makes one complete revolution. In the retracted condition the diameter of the lowest turn of the larger side of the crown is slightly greater than half the breadth of the thorax. As a result the radius of curvature of the whorls of the crown diminishes slowly (Fig. I B). When the crown is retracted the dorsal edges of the two sides of the crown nearly touch at the level of the basal membrane. Viewed from the ventral surface the two sides of the branchial crown do not overlap, both turning inwards medially (Fig. $2 \mathrm{~B}$ ). The palps are variable in form, 
commonly short and ending bluntly, but they may be long, with fine tips as in S. pavonina. They are usually bent (Fig. $3 \mathrm{~B}, \mathrm{C}$ ).

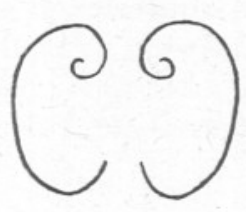

A
Ventral

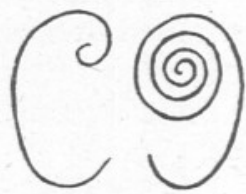

Dorsal

B

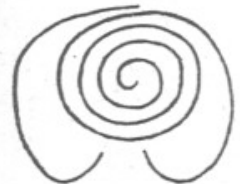

C

Fig. 2. Projection, in the transverse plane, of the rachis of the crowns of A, Sabella pavonina; $\mathrm{B}, \mathrm{S}$. pavonina var. bicoronata; and C, Spirographis spallanzanii. Note that the lesser side of the crown of Spirographis makes only half a revolution and overlaps the greater half of the crown ventrally.

The dorsal collar fold arises immediately dorsal to the first chaetal bundle (Fig. I B). When reflected anteriorly the folds cover not more than half the length of the peristomium. The sides of the peristomial depression across which the ciliated faecal groove runs are never raised to form thin lips (Fig. 4A).

The ventral edge of the uncinal ridge of the second thoracic chaetigerous segment is separated from the dorsal edge of the ventral gland shield by at least half the length of the ridge (Fig. 4A, u.r.).

The blood vascular systems of Sabella pavonina and Spirographis spallanzanii have lately been described (Ewer, I94I). In the abdomen of the variety bicoronata the arrangement of the blood vessels differs only slightly from that of $S$. pavonina. There is no sign of the septal plexus or of capillaries in the ventral muscle blocks which are characteristic of $S$. spallanzanii. Fox (1946) has examined the spectra of the chlorocruorins of $S$. pavo-
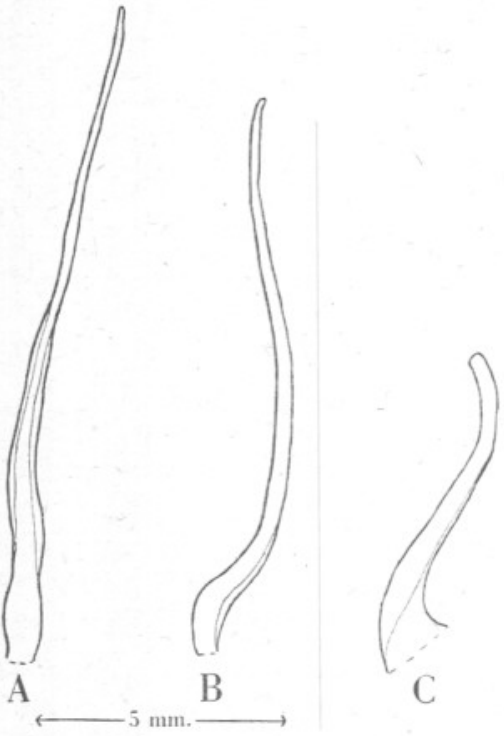

C

Fig. 3. Palps of A, Sabella pavonina; B and $\mathrm{C}$, its variety bicoronata.

nina, the bicoronata variety and $S$. spallanzanii. His results may be summarized as follows. The wave length of the $\alpha$-band of oxychlorocruorin in $S$. pavonina is 606I A.; in var. bicoronata it is $8 \mathrm{~A}$. shorter and in S. spallanzanii II A. shorter. The span (difference between the $\alpha$-band wave lengths in the oxy-and carboxy-compounds) is the same in S. pavonina and var. bicoronata, but differs in S. spallanzanii. 


\section{SPIROGRAPHIS SPALLANZANII VIVIANI}

The number of branchial filaments is very unequal on the two sides of the crown. Typical counts on adult specimens are 36-I38, 28-I62 and 43-IO9. The rachis of the crown on the greater side is spirally rolled and may make more than four complete revolutions. On the lesser side the rachis makes only half a revolution. In the retracted condition the diameter of the lowest complete turn of the greater side of the crown is slightly less than the breadth of the thorax. The radius of curvature of the whorls of the crown diminishes rapidly. When the crown is retracted the dorsal edges of the two sides of the crown almost touch at the level of the basal membrane (Fig. I C). Viewed

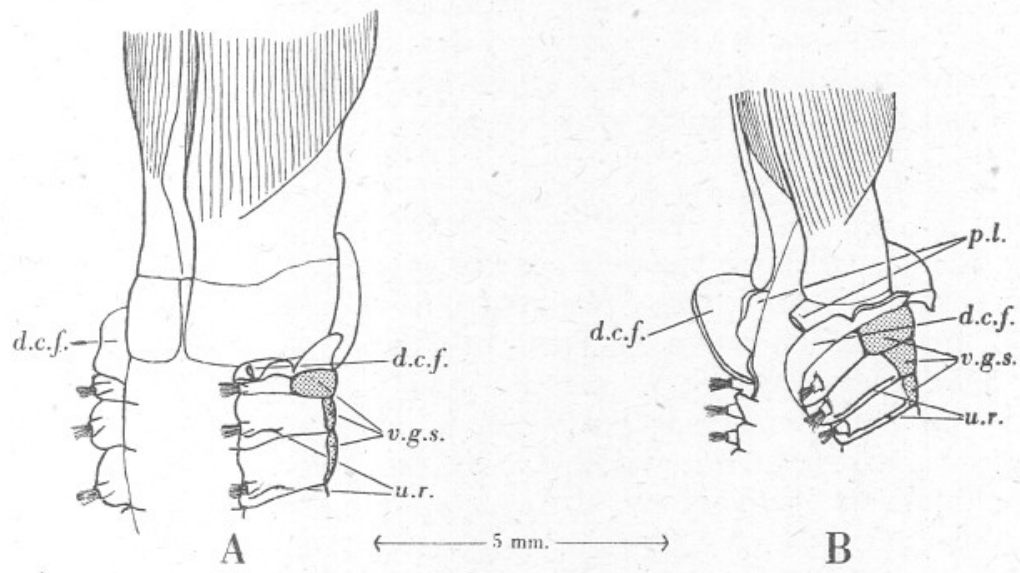

Fig. 4. Sketch of the peristomial region of A, Sabella pavonina var. bicoronata; and B, Spirographis spallanzanii. d.c.f. dorsal collar fold; p.l. peristomial lip; u.r. uncinal ridge; v.g.s. ventral gland shield.

from the ventral surface the lesser side of the branchial crown overlaps the greater. The free edge of the lesser side does not turn inwards medially (Fig. 2 C). The palps are short, end in a fine tip and are never more than three times the length of the membrane which joins them proximally.

The dorsal collar fold arises more dorsally than the first chaetal bundle (Fig. I C), the two halves of the collar fold often almost touch. When reflected anteriorly the dorsal folds cover the whole length of the peristomium. The sides of the peristomial depression across which the ciliated faecal track runs are nearly always raised to form thin lips, which run along the edges of the groove (Fig. 4 B, p.l.).

The ventral edge of the uncinal ridge of the second thoracic chaetigerous segment usually touches the dorsal edge of the ventral gland shield, but may be separated from it by less than half the length of the ridge (Fig. 4 B, u.r.). 
The Systematic Position of SABELLA PAVONINA VAR. BICORONATA

Hornell (I89I) considered that the specimens from Hilbre Island were a variety of Sabella pavonina for they only differed from the normal form in the development of the crown. As shown above the palps may also be different.

In $S$. pavonina and the variety bicoronata the ventral edge of the uncinal ridge of the second thoracic chaetiger is well separated from the dorsal edge of the ventral gland shield. In Spirographis spallanzanii the two structures almost touch. The condition in this latter species is also found in all other species of Sabella which I was able to study at the British Museum. These were $S$. crassicornis Sars, S. oatesiana Benham, S. bipuntulata Baird, S. nigromaculata Baird and $S$. fusca Grube. This fact emphasizes the close relation between Hornell's variety bicoronata and the normal pavonina type.

I therefore consider that there is insufficient reason for reversing Hornell's opinion and raising his variety to a species.

\section{The GenUS SPIROGRAPHIS}

As has been stated above, the only positive generic character which has been used to separate Sabella from Spirographis, namely the inequality of the two sides of the branchial crown, is shown by Hornell's variety of Sabella. The other differences between $S$. pavonina and Spirographis spallanzanii are certainly not worthy of being made generic in value, especially as many of them are characters which are variable within the two genera. For example, the form of the rachis of the crown in Spirographis braziliensis Treadwell is the same as that in the variety bicoronata; palps as short as those in S. spallanzanii are also found in the bicoronata variety of Sabella pavonina; the dorsal origin of the collar folds is variable in position-in Sabella nudicollis Pruvot they arise at the level of the third chaetigerous segment. There are, moreover, no noteworthy differences between the chaetae of $S$. pavonina, its variety bicoronata and Spirographis spallanzanii.

For these reasons it is considered that the genus Spirographis is not valid and that species previously assigned to this genus should be referred to Sabella.

The genus Sabella would then be defined as follows:

Body cylindrical or subcylindrical. Two branchial lobes of which at least one is not rolled spirally. Branchial filaments lack dorsal appendages and subterminal eyes, but paired eye spots may occur. Ventral gland shields rectangular and divided into two portions in the abdomen by the faecal groove. Two palps. One dorsal and two ventral lips. Collar bi- or quadrilobed. In the thorax the neuropodium has avicular uncini and pennoned chaetae, the notopodium chaetae with narrow wings. No uncini or pennoned chaetae in the first chaetigerous segment. In the abdomen avicular uncini occur dorsally, chaetae with narrow wings ventrally. 
My thanks are due to Mr D. P. Wilson, of the Marine Biological Association, who drew my attention to this variety of Sabella, to the Director of the Laboratoire Lacaze-Duthiers, Roscoff, who kindly gave me many specimens of Spirographis and to both the Director of the Marine Biological Laboratory at Plymouth and Professor H. Munro Fox, F.R.S., in whose laboratories this, work was undertaken.

\section{SUMMARY}

A variety of Sabella pavonina Sav. described by Hornell as bicoronata has been found at Plymouth. It is characterized by the unequal development of the two sides of the branchial crown. The characters by which Sabella pavonina, its variety bicoronata and Spirographis spallanzanii may be distinguished are described. It is concluded that the genus Spirographis is not valid and that its species should be referred to the genus Sabella which is redefined.

\section{REFERENCES}

EwER, D. W., I94I. The blood systems of Sabella and Spirographis. Quart. Fourn. Micr. Sci., Vol. 82, p. 587.

Fauvel, P., 1927. Polychètes sédentaires. Faune de France, I6. Paris.

Fox, H. M., 1946. Chemical Taxonomy. Nature, Vol. 157, p. 5 I I.

Hornell, J., I89I. Report on the Polychaetous Annelids of the L.M.B.C. District. Proc. Liverpool Biol. Soc., Vol. 5, p. 223.

Johansson, K. E., I927. Polychaeten-Familien Hermellidae, Sabellidae und Serpulidae. Zool. Bidr. Uppsala, Bd. II, p. I. 